\title{
Characterization of Hairy-Spored Streptomycetes
}

\section{Twelve Additional Cultures}

\author{
ALMA DIETZ AND JOHN MATHEWS \\ Research Laboratories, The Upjohn Company, Kalamazoo, Michigan 49001
}

Twelve Streptomyces species having hairy spores were examined by transmission electron microscopy and scanning electron microscopy. Each species was assigned to one of the three previously proposed subgroups of the hairy-spored group.

In previous papers we established the conditions for culture growth and electron microscopic examination of streptomycete spores (13 ) and classification of these spores into five groups (4). In another paper (5), we characterized eight members of the hairy-spored streptomycete group and designated three subgroups based on spore morphology and length and abundance of hairs.

In this paper we present the electron microscopic characteristics of spores from twelve additional hairy-spored streptomycetes chosen from the twenty-one International Streptomyces Project (ISP) type cultures that were found to have hairy spores (6-8). The twelve cultures chosen for study are listed in Table 1.

The accompanying figures show the appearance by transmission electron microscopy of whole spores picked up on carbon-filmed grids and the appearance by scanning electron microscopy of intact cultures grown in situ on cover glasses. All cultures have spores bearing flexible filaments (hairs) which fulfills the criterion for inclusion in the hairy-spored group.

Subgroup assignment is as follows.

Subgroup A. Characterized by tightly coiled spiral spore chains with spores having large numbers of long hairs. Streptomyces (Actinomyces) finlayi (Fig. 3 and 4) and S. karnatakensis (Fig. 15 and 16) were classified in this group.

Subgroup B. Characterized by straight or loosely coiled spore chains with spores bearing fewer and shorter hairs than those of subgroup A. S. (A.) flavoviridis (Fig. 5 and 6), S. (A.) glaucescens (Fig. 7 and 8), S. flaveolus (Fig. 11 and 12), S. lucensis (Fig. 17 and 18), S. (A.) malachitofuscus (Fig. 19 and 20), and S. prasinopilosus (Fig. 23 and 24) were classified in this group.

Subgroup C. Characterized by flexuous spore chains with few hairs on each spore (baldheaded). S. (A.) acrimycini (Fig. 1 and 2), $S$. (A.) heimi (Fig. 9 and 10), S. (A.) griseomycini
TABLE 1. Hairy-spored ISP streptomycetes chosen for study

\begin{tabular}{ccc}
\hline Cultures & ISP $^{a}$ & UC $^{b}$ \\
\hline $\begin{array}{l}\text { Streptomyces }\left(\text { Actinomyces }^{c} \text { ) ac- }\right. \\
\text { rimycini }\end{array}$ & 5135 & $\mathbf{5 5 5 4}$ \\
$\begin{array}{l}\text { Streptomyces }\left(\text { Actinomyces }^{c} \text { ) }\right. \\
\text { fintayi }\end{array}$ & 5218 & 5563
\end{tabular}

finlayi

Streptomyces (Actinomyces $^{c}$ ) $\quad 5153 \quad 5556$

flavoviridis

Streptomyces (Actinomyces $^{c}$ ) $\quad 5155 \quad 5557$

glaucescens

Streptomyces (Actinomyces ${ }^{c}$ ) $\quad 5328 \quad 5564$

heimi

Streptomyces flaveolus $\quad 5061$

Streptomyces (Actinomyces) gri-

seomycini

Streptomyces karnatakensis $\quad \mathbf{5 3 4 5} \quad \mathbf{5 5 6 5}$

Streptomyces lucensis $\quad 5317 \quad 5566$

Streptomyces (Actinomyces) ma- $5332 \quad 5567$ lachitofuscus

Streptomyces pilosus $\quad \mathbf{5 0 9 7} \quad \mathbf{5 5 6 0}$

Streptomyces prasinopilosus $\quad 5098 \quad 5561$

${ }^{a}$ International Streptomyces Project number.

${ }^{b}$ Upjohn culture number.

${ }^{c}$ Used with ISP illustration.

(Fig. 13 and 14), and S. pilosus (Fig. 21 and 22) were classified in this group.

The remaining ISP hairy-spored cultures as well as other hairy-spored cultures will be included in a later study.

\section{REPRINT REQUESTS}

Address reprint requests to: Alma Dietz, Research Laboratories, The Upjohn Co., Kalamazoo, MI 49001.

\section{LITERATURE CITED}

1. Dietz, A., and J. Mathews. 1962. Taxonomy by carbon replication. I. An examination of Streptomyces $h y$ groscopicus. Appl. Microbiol. 10:258-263.

2. Dietz, A., and J. Mathews. 1968. Taxonomy by carbon replication. II. Examination of eight additional cultures of Streptomyces hygroscopicus. Appl. Microbiol. 16:935-941.

3. Dietz, A., and J. Mathews. 1969. Scanning electron microscopy of selected members of the Streptomyces hygroscopicus group. Appl. Microbiol. 18:694-696.

4. Dietz, A., and J. Mathews. 1971. Classification of Strep- 

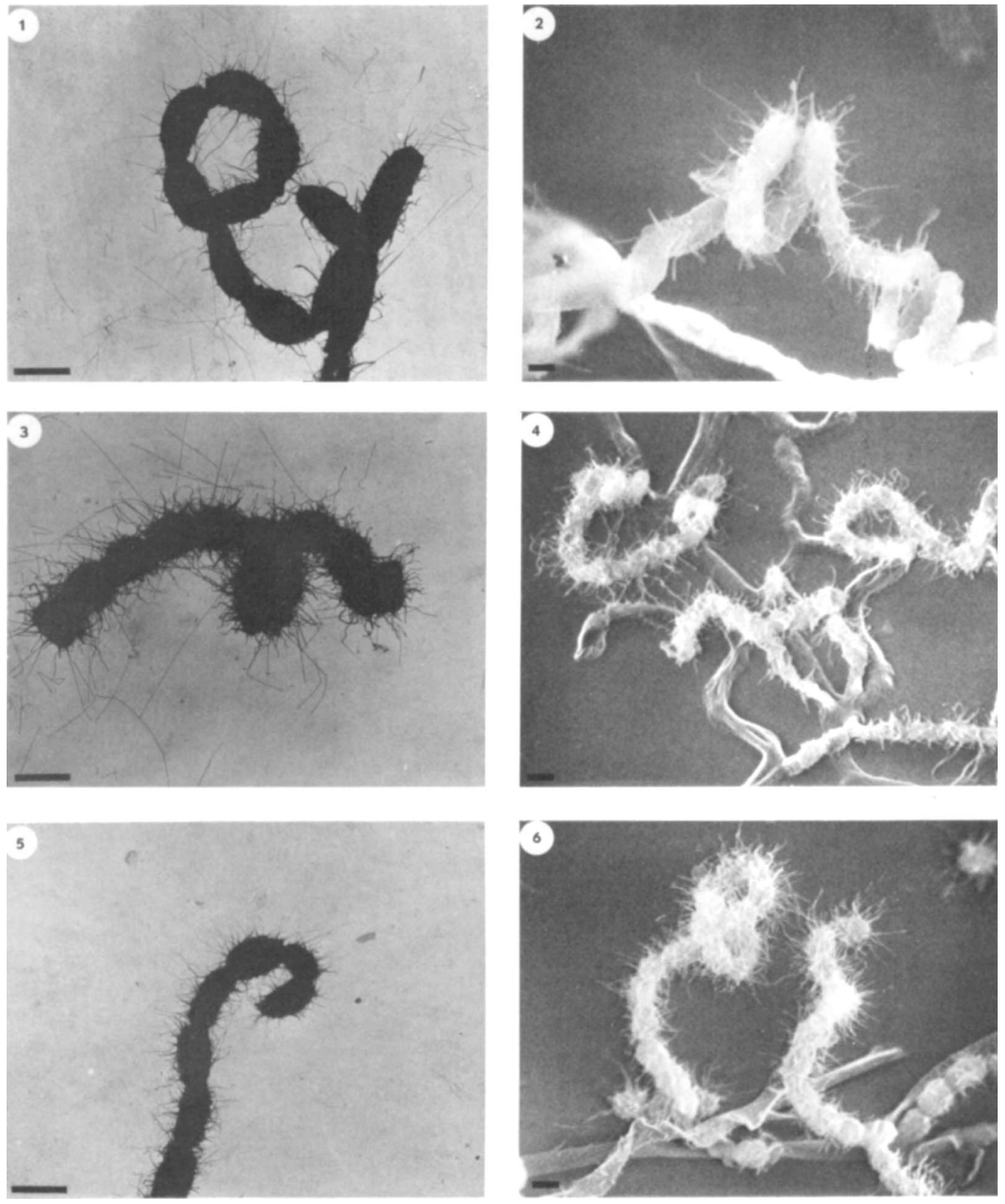

FIG. 1-24. Bar represents $1 \mu \mathrm{m}$. Abbreviations: TEM, transmission electron microscopy; SEM, scanning electron microscopy.

FIG. 1 and 2. Streptomyces (Actinomyces) acrimycini ISP 5135 (UC 5554). (1) Whole spores by TEM; (2) intact culture by SEM. Subgroup C.

FIG. 3 and 4. Streptomyces (Actinomyces) finlayi ISP 5218 (UC 5563). (3) Whole spores by TEM; (4) intact culture by SEM. Subgroup A.

FIG. 5 and 6. Streptomyces (Actinomyces) flavoviridis ISP 5153 (UC 5556). (5) Whole spores by TEM; (6) intact culture by SEM. Subgroup B. 

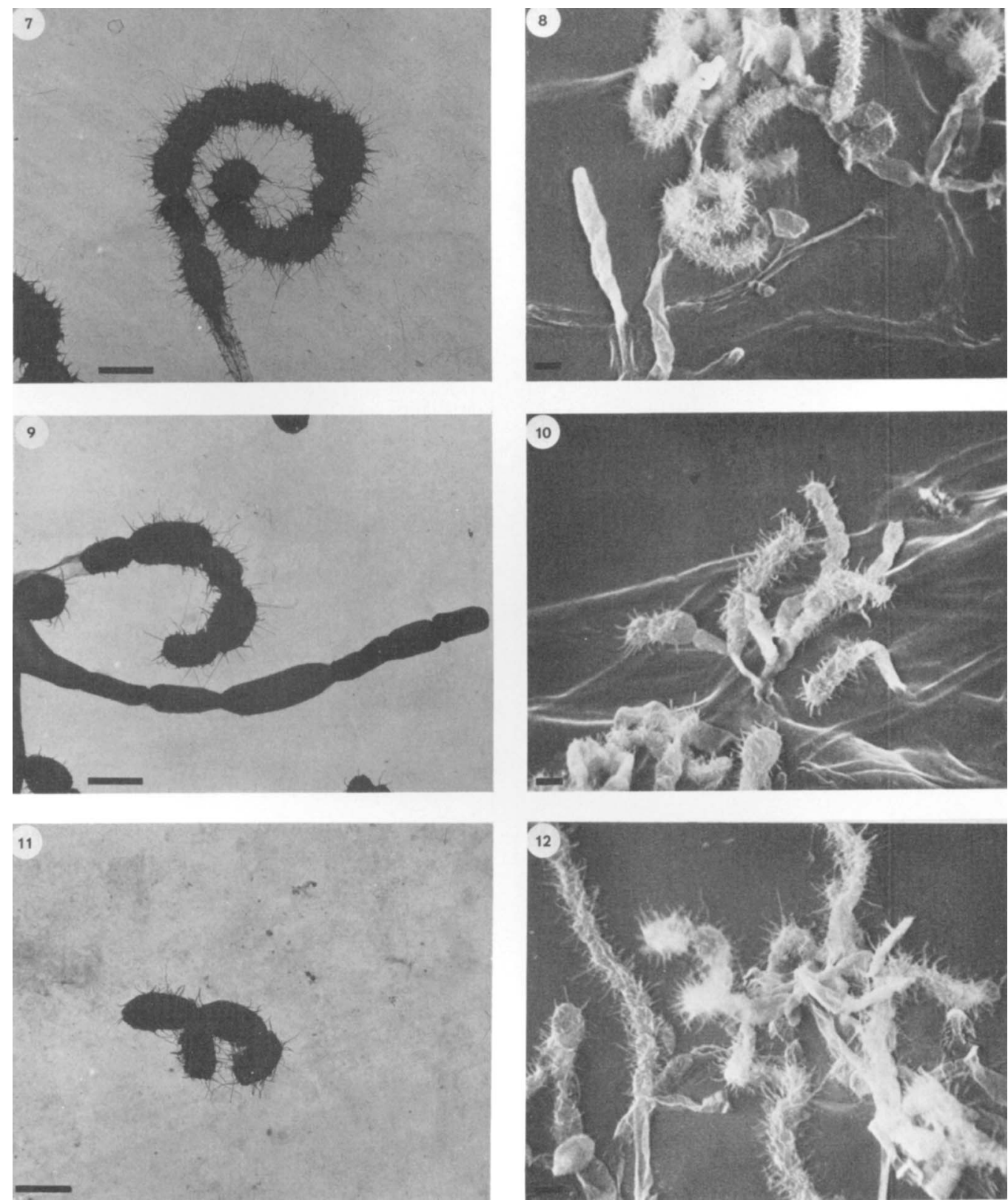

FIG. 7 and 8. Streptomyces (Actinomyces) glaucescens ISP 5155 (UC 5557). (7) Whole spores by TEM; (8) intact culture by SEM. Subgroup B.

FIG. 9 and 10. Streptomyces (Actinomyces) heimi ISP 5328 (UC 5564). (9) Whole spores by TEM; (10) intact culture by SEM. Subgroup C.

FIG. 11 and 12. Streptomyces flaveolus ISP 5061 (UC 5555). (11) Whole spores by TEM; (12) intact culture by SEM. Subgroup $B$. 

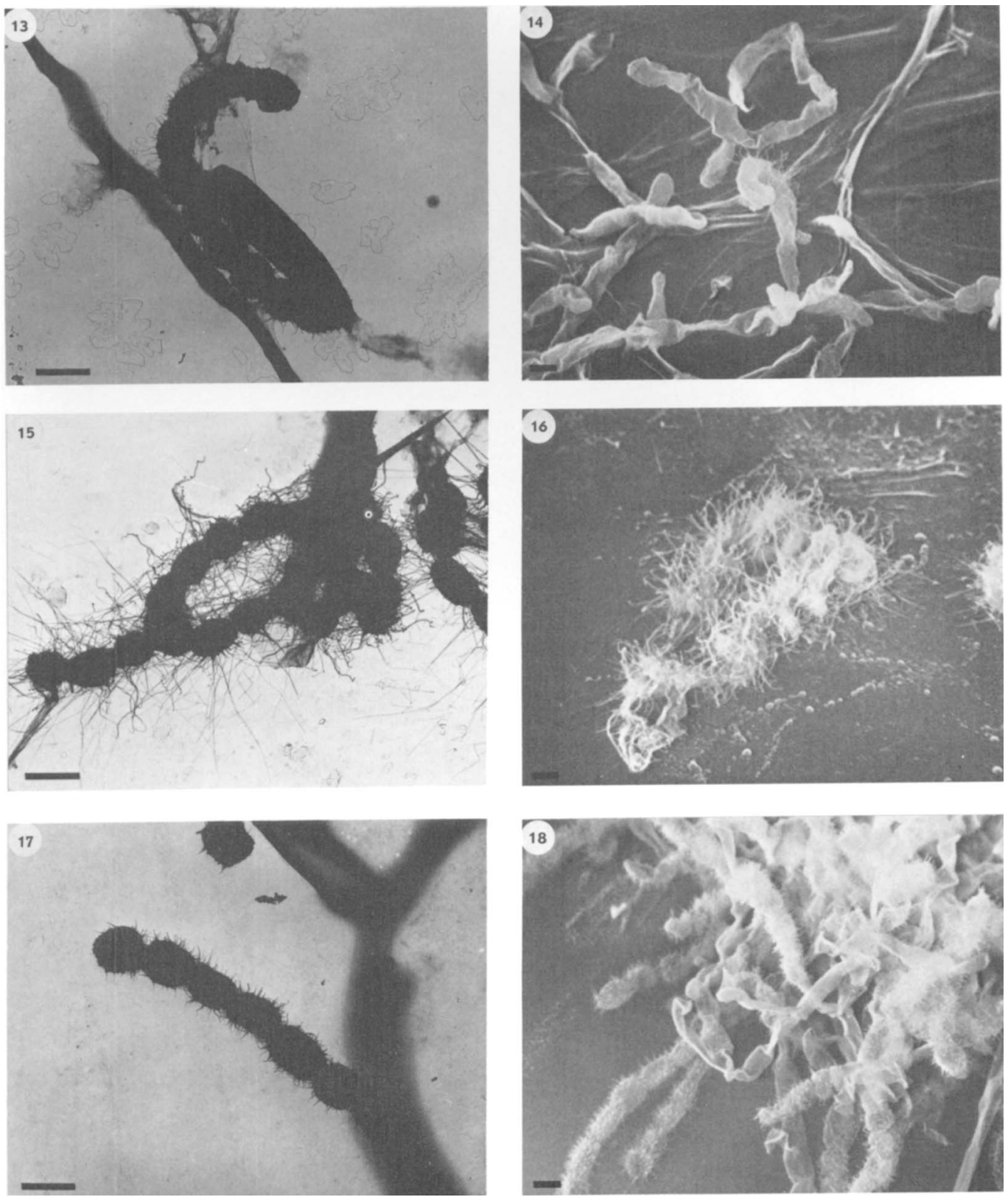

FIG. 13 and 14. Streptomyces (Actinomyces) griseomycini ISP 5159 (UC 5558). (13) Whole spores by TEM; (14) intact culture by SEM. Subgroup C.

FIG. 15 and 16. Streptomyces karnatakensis ISP 5345 (UC 5565). (15) Whole spores by TEM; (16) intact culture by SEM. Subgroup A.

Fig. 17 and 18. Streptomyces lucensis ISP 5317 (UC 5566). (17) Whole spores by TEM; (18) intact culture by SEM. Subgroup B. 

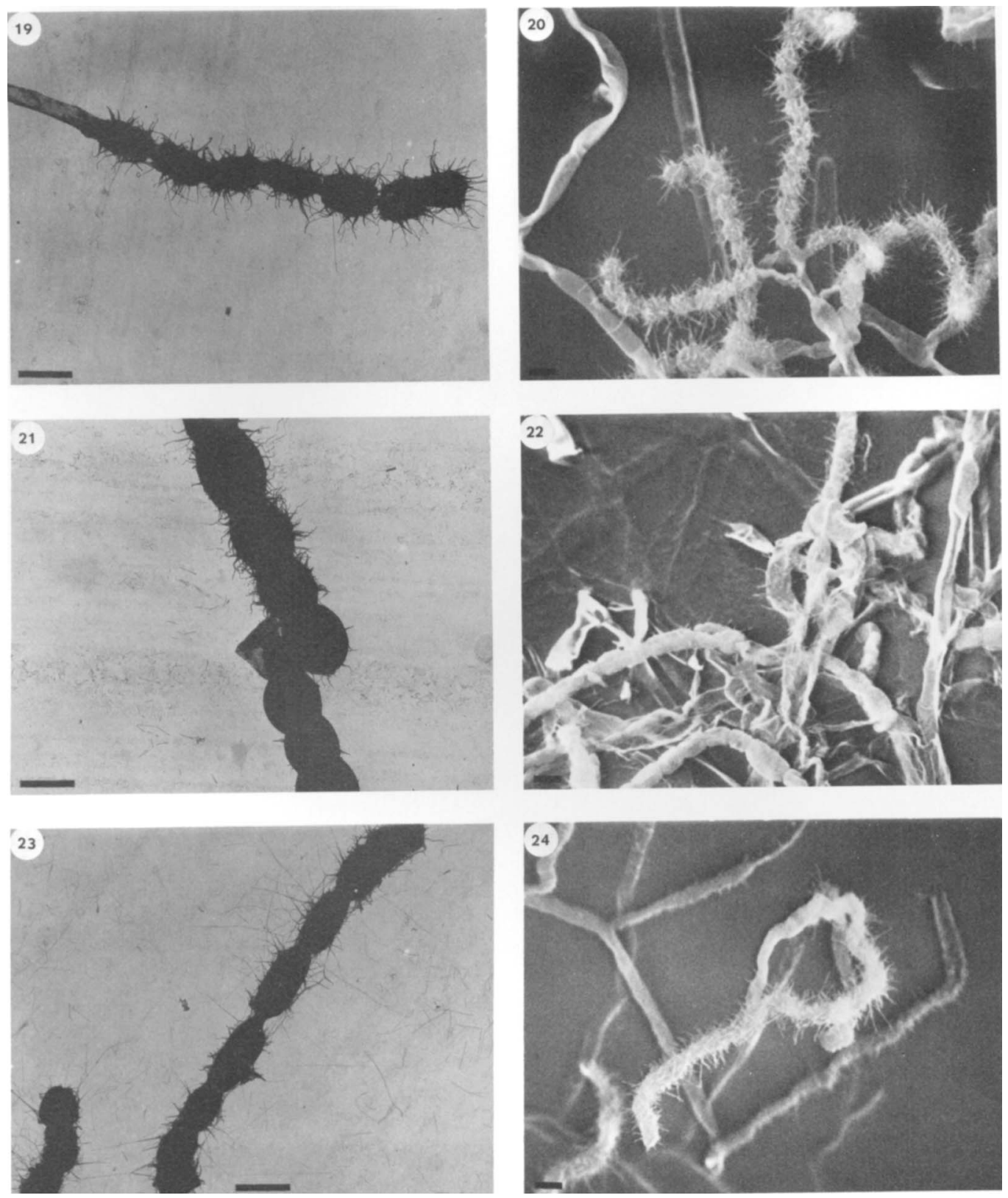

FIG. 19 and 20. Streptomyces (Actinomyces) malachitofuscus ISP 5332 (UC 5567). (19) Whole spores by TEM; (20) intact culture by SEM. Subgroup B.

FIG. 21 and 22. Streptomyces pilosus ISP 5097 (UC 5560). (21) Whole spores by TEM; (22) intact culture by SEM. Subgroup C.

FIG. 23 and 24. Streptomyces prasinopilosus ISP 5098 (UC 5561). (23) Whole spores by TEM; (24) intact spores by $S E M$. Subgroup $B$. 
tomyces spore surfaces into five groups. Appl. Microbiol. 21:527-533.

5. Dietz, A., and J. Mathews. 1972. Characterization of hairy-spored streptomycetes. Int. J. Syst. Bacteriol. 22:173-177.

6. Shirling, E. B., and D. Gottlieb. 1968. Comparative description of type cultures of Streptomyces. II. Species descriptions from first study. Int. J. Syst. Bacteriol. 18:69-189.
7. Shirling, E. B., and D. Gottlieb. 1968. Cooperative description of type cultures of Streptomyces. III. Additional species descriptions from first and second studies. Int. J. Syst. Bacteriol. 18:279-392.

8. Shirling, E. B., and D. Gottlieb. 1969. Cooperative description of type cultures of Streptomyces. IV. Species descriptions from the second, third and fourth studies. Int. J. Syst. Bacteriol. 19:391-512. 